\title{
Surgical practice patterns and outcomes in T2 and T3 gallbladder cancer: a population-based study
}

\author{
Senthuran Tharmalingam, MD, \\ MSc \\ Jennifer Flemming, MD, MAS \\ Harriet Richardson, PhD \\ David Hurlbut, MD \\ Sean Cleary, MD, MSc \\ Sulaiman Nanji, MD, PhD
}

\begin{abstract}
This work was presented as an oral presentation at the Americas Hepato-Pancreato-Biliary Association 2017 annual meeting, Mar. 29-Apr. 2, 2017, Miami, Fla. It was presented in part as a poster at the Canadian Surgery Forum 2017, Sept. 14-17, 2017, Victoria, BC.
\end{abstract}

Accepted Oct. 26, 2021

\section{Correspondence to:}

$\mathrm{S}$. Tharmalingam

Department of Surgery

Queen's University

76 Stuart St

Kingston ON K7L 2V7

11st21@queensu.ca

Cite as: Can J Surg 2022 January 11; 65(1). doi: 10.1503/cjs.019719

\begin{abstract}
Background: The extent of resection required in advanced gallbladder cancer is controversial. We aimed to describe the management and outcomes in patients with resected stage $\mathrm{T} 2$ and $\mathrm{T} 3$ gallbladder cancer.

Methods: In this population-based study, all T2 and T3 gallbladder cancer cases from Jan. 1, 2002, to Mar. 31, 2012, were identified from the Ontario Cancer Registry; pathology reports were linked and abstracted. The type of resection was classified as extended (cholecystectomy + liver resection, with or without bile duct resection) or simple (cholecystectomy only). We used Kaplan-Meier survival analysis to model time to death and evaluated factors associated with overall survival using the Cox proportional hazards regression model.
\end{abstract}

Results: A total of 370 patients were included, 232 with T2 disease and 138 with T3 disease. The proportions who underwent extended resection were $24.1 \%(56 / 232)$ and $37.0 \%(51 / 138)$, respectively. The unadjusted 5 -year overall survival rates for simple and extended resection were $39.7 \%$ and $49.5 \%$, respectively, for T2 disease $(p=0.03)$, and $13.5 \%$ and $22.8 \%$, respectively, for T3 disease $(p=0.05)$. In adjusted analysis, extended resection significantly improved overall survival among patients with T2 disease (hazard ratio [HR] $0.51,95 \%$ confidence interval [CI] $0.30-0.97$ ), whereas higher grade of differentiation, presence of lymphovascular invasion and positive lymph nodes led to worse survival. Extended resection was not associated with improved survival in the T3 group; however, in subgroup analysis stratified by lymph node status, a trend toward improved overall survival with extended resection was seen in node-negative patients (HR 0.20, 95\% CI 0.03-1.06).

Conclusion: Extended resection improved overall survival in T2 disease regardless of nodal status but appeared most beneficial in node-negative T3 disease. The finding that extended resection was offered only to a small proportion of eligible patients highlights the need for improved knowledge translation at national surgical meetings.

Contexte : On ne s'entend pas sur l'ampleur de la résection requise dans les cas de cancer avancé de la vésicule biliaire. Nous avons voulu décrire la prise en charge et les résultats chez les patients opérés pour résection d'un cancer de la vésicule biliaire de stades $\mathrm{T} 2$ et $\mathrm{T} 3$.

Méthodes : Dans cette étude basée dans la population, tous les cas de cancer de la vésicule biliaire de stades T2 et T3 entre le $1^{\text {er }}$ janvier 2002 et le 31 mars 2012 ont été identifiés à partir du Registre des cas de cancer de l'Ontario; les rapports d'anatomopathologie ont été reliés et résumés. La résection était classée soit élargie (cholécystectomie + résection hépatique, avec ou sans résection du canal cholédoque) ou simple (cholécystectomie seulement). Nous avons utilisé l'analyse de survie de Kaplan-Meier pour modéliser la durée de la survie et évalué les facteurs associés à la survie globale à l'aide du modèle de régression aléatoire proportionnelle de Cox.

Résultats : En tout, 370 patients ont été inclus, dont 232 présentaient un stade T2 et 138 un stade T3. Les proportions soumises à une résection élargie ont été de 24,1\% $(56 / 232)$ et $37,0 \%(51 / 138)$, respectivement. Les taux de survie globaux non ajustés à 5 ans pour les résections simples et élargies ont été de $39,7 \%$ et de $49,5 \%$, respectivement, pour les T2 $(p=0,03)$, et de $13,5 \%$ et de $22,8 \%$, respectivement pour les T3 $(p=0,05)$. Dans l'analyse ajustée, la résection élargie a significativement amélioré la survie globale chez les patients au stade T2 (rapport de risques [RR] 0,51, intervalle de confiance [IC] de $95 \% 0,30-0,97)$, tandis qu'un degré plus élevé de différenciation, la présence d'envahissement lymphovasculaire et de ganglions lymphatiques positifs ont donné lieu à une survie moindre. La résection élargie n'a pas été associée à une amélioration de la survie dans le groupe T3; par contre, dans une analyse de sous-groupes 
stratifiés en fonction de l'atteinte des ganglions lymphatiques, nous avons observé une tendance à l'amélioration globale de la survie après la résection élargie chez les patients dont les ganglions étaient négatifs (RR 0,20, IC de $95 \%$ 0,03-1,06).

Conclusion : La résection élargie a amélioré la survie globale des patients au stade T2, indépendamment de l'atteinte ganglionnaire, mais a semblé plus bénéfique chez les patients au stade T3 dont les ganglions étaient négatifs. Le fait que la résection élargie n'ait été offerte qu'à une faible proportion de patients admissibles rappelle qu'il faut insister davantage sur l'application des connaissances lors des congrès nationaux de chirurgie.

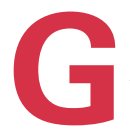
allbladder cancer is a rare but highly lethal malignant disorder. Historically, it had been deemed a terminal illness with 5 -year survival rates varying from $0 \%$ to $12 \%$ and a median survival of 6.4 months. ${ }^{1,2}$ Surgery offers the only chance of cure. ${ }^{3}$ Although recent guidelines suggest that stage T2 and T3 gallbladder cancers should be treated with extended cholecystectomy, high-level evidence is lacking because these guidelines are mostly based on observational, single-institution studies. ${ }^{4}$ Therefore, the extent of surgical resection for T2 and T3 gallbladder cancer remains an important field of study in hepatobiliary surgery.

The aim of the current study was to describe the association between the extent of surgical resection and overall survival in patients with T2 or T3 gallbladder cancer in a large contemporary population-based cohort.

\section{Methods}

\section{Study design and setting}

This was a population-based retrospective cohort study of all surgically resected gallbladder cancers in Ontario, Canada. Ontario has a population of about 13.5 million people and a single-payer health insurance program that provides coverage for physician and hospital services.

\section{Study population and data sources}

All incident cases of gallbladder cancer from Jan. 1, 2002, to Mar. 31, 2012, were identified from the Ontario Cancer Registry (OCR), a passive, population-based cancer registry that captures diagnostic and demographic information for $98 \%$ of all incident cases of cancer in Ontario. ${ }^{5} \mathrm{We}$ obtained surgical pathology reports from the OCR for all potentially eligible patients. We excluded all patients in whom the $\mathrm{T}$ stage could not be determined, patients with gallbladder cancer with histologic findings of disease other than adenocarcinoma or adenosquamous carcinoma, and patients with metastatic gallbladder cancer at initial surgery. We identified patients who had undergone cholecystectomy and subsequent re-resection based on the presence of 2 separate pathology reports on different dates, 1 for cholecystectomy and the other for extended resection. We defined simple cholecystectomy as removal of the gall- bladder only, and extended resection as cholecystectomy with upfront or delayed partial resection of the liver or bile duct or both.

The OCR also provides information about vital status and cause of death. Complete information regarding vital status was available up to Dec. 31, 2012, and information concerning cause of death was available up to Dec. 31, 2010.

As per ICES and Cancer Care Ontario policy, values for cells with fewer than 6 cases were suppressed; results in these fields were reported as approximate values to ensure confidentiality. The study was approved by the General Research Ethics Board of Queen's University, Kingston, Ont.

\section{Adjuvant treatment}

Radiotherapy and chemotherapy databases are maintained at the Division of Cancer Care and Epidemiology, Queen's University with permission from all 14 Ontario cancer centres. Using the unique identifier for each patient in the OCR, the division links the cancer diagnosis from the OCR to chemotherapy and radiotherapy administration data from the cancer centres. Only curative-intent adjuvant treatment was included in the present study.

\section{Socioeconomic status}

For the purpose of our study, we estimated socioeconomic status using an ecologic measure: patient's neighbourhood median household income. We obtained median household income at the level of the dissemination area from Statistics Canada. Dissemination areas were grouped into quintiles based on median household income, with the fifth quintile constituting the wealthiest $20 \%$ and the first quintile constituting the poorest $20 \%$.

\section{Primary and secondary outcomes}

The primary outcome was overall survival, and the secondary outcome was cancer-specific survival.

\section{Statistical analysis}

We conducted all analysis using SAS 9.4 (SAS Institute). We used Kaplan-Meier survival analysis to model time to death, with censoring occurring on Dec. 31, 2012, for 
overall survival and Dec. 31, 2010, for cancer-specific survival. We evaluated factors associated with overall survival using the Cox proportional hazards regression model. Before building the Cox model, we conducted bivariate analysis on the following potential confounding variables: age, sex, socioeconomic status, presence or absence of lymphovascular invasion and perineural invasion, positive lymph nodes and adjuvant treatment. On bivariate analysis, socioeconomic status and adjuvant treatment failed to achieve a $p<0.2$ for both $\mathrm{T} 2$ and $\mathrm{T} 3$ and were therefore excluded from the full Cox model.

Margin status was not included in the Cox model as it caused a significant multicollinearity effect in our model. There was a high Pearson correlation coefficient $\left(r^{2}=0.84\right)$ between margin status and type of resection (exposure variable). When margin status was forced into the Cox model, it led to large, erratic changes in the regression coefficient of the other predictor variables. It can thus be conceptualized that margin status is simply a surrogate marker for type of surgery in that patients who underwent extended resection tended to have negative margins.

\section{Results}

Linked administrative data sets identified 1055 potentially eligible patients who underwent a procedure for gallbladder cancer from Jan. 1, 2002, to Mar. 31, 2012, of whom 500 were excluded because they had a biopsy procedure only. Following all exclusion criteria, 370 patients constituted the study cohort, 232 with T2 disease and 138 with T3 disease (Figure 1).

Patient, treatment and pathology variables are shown in Table 1. Of the 232 patients with T2 disease, 176 (75.9\%) had simple cholecystectomy and 56 (24.1\%) had extended resection. Patients who underwent simple cholecystectomy were older on average than those who underwent extended resection (mean age $69.8 \mathrm{yr}$ v. $63.4 \mathrm{yr}$ ). In the extendedresection group, 23 (42.8\%) had upfront extended resection and $33(57.1 \%)$ had delayed extended resection. Delayed resection procedures took place a mean of 2.9 (range 1.0-5.0) months after initial cholecystectomy.

Of the 138 patients with T3 disease, $87(63.0 \%)$ had simple cholecystectomy and $51(37.0 \%)$ had extended resection. As in the T2 group, patients who underwent simple cholecystectomy were older on average than those who underwent extended resection (mean age $70.0 \mathrm{yr}$ v. $66.3 \mathrm{yr}$ ). Thirty-six patients $(72.5 \%)$ underwent upfront extended resection, and 15 (29.4\%) had delayed extended resection. Delayed resection procedures were performed a mean of 2.2 (range 1.2-5.0) months after initial cholecystectomy.

\section{Survival}

In the T2 group, the 5-year unadjusted overall survival rate for patients who underwent extended

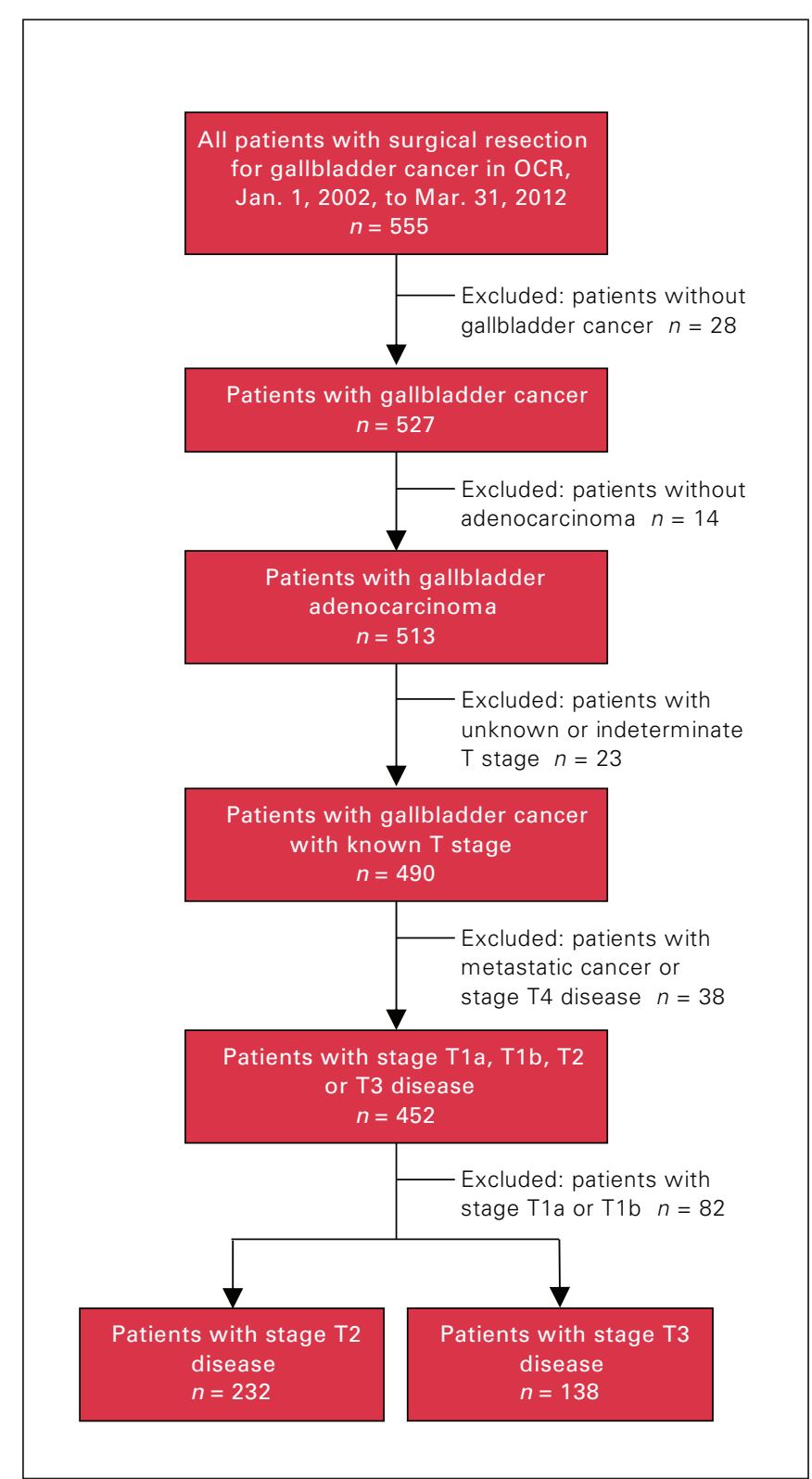

Fig. 1. Flow diagram showing identification of patients with stage T2 or T3 gallbladder cancer who underwent surgical resection in Ontario, Jan. 1, 2002, to Mar. 31, 2012. OCR = Ontario Cancer Registry.

resection was $49.5 \%$, compared to $39.7 \%$ for those who had simple cholecystectomy $(p=0.03)$ (Figure 2A). The 5-year cancer-specific survival rates were $49.9 \%$ and $41.3 \%$, respectively $(p=0.03$ ). The median overall survival was more than 60 months for extended resection, compared to 23 months for simple resection $(p=0.08)$. The 30 -day postoperative mortality rate was $1.7 \%$ for both simple cholecystectomy and extended resection.

In T3 disease, the 5-year unadjusted overall survival rate was $22.8 \%$ for patients who underwent extended resection and $13.5 \%$ for those who underwent simple 
Table 1. Characteristics of patients with stage T2 or T3 gallbladder cancer who underwent surgical resection in Ontario, Jan. 1, 2002, to Mar. 31, 2012

\begin{tabular}{|c|c|c|c|c|c|c|}
\hline \multirow[b]{2}{*}{ Characteristic } & \multicolumn{3}{|c|}{ T2; no. (\%) of patients* } & \multicolumn{3}{|c|}{ T3; no. (\%) of patients* } \\
\hline & $\begin{array}{c}\text { All } \\
n=232\end{array}$ & $\begin{array}{l}\text { Simple } \\
n=176\end{array}$ & $\begin{array}{c}\text { Extended } \\
n=56\end{array}$ & $\begin{array}{c}\text { All } \\
n=138\end{array}$ & $\begin{array}{l}\text { Simple } \\
n=87\end{array}$ & $\begin{array}{c}\text { Extended } \\
n=51\end{array}$ \\
\hline $18-60$ & $62(26.7)$ & $41(23.3)$ & $21(37.5)$ & $35(25.4)$ & $15-20(17.2-23.0)$ & $15-20(29.4-39.2)$ \\
\hline $61-80$ & $131(56.5)$ & $95-100(54.0-56.8)$ & $30-35(53.6-62.5)$ & $83(60.1)$ & $51(58.6)$ & $32(62.7)$ \\
\hline$\geq 81$ & 39 (16.8) & $35-40(19.9-22.7)$ & $<6(0.0-8.9) \dagger$ & $20(14.5)$ & $15-20(17.2-23.0)$ & $<6(0.0-9.8) \dagger$ \\
\hline Female & $156(67.2)$ & $116(65.9)$ & $40(71.4)$ & $99(71.7)$ & 59 (67.8) & $40(78.4)$ \\
\hline Male & 75 (32.3) & $60(34.1)$ & $15(26.8)$ & $39(28.3)$ & $28(32.2)$ & $11(21.6)$ \\
\hline Missing & $1(0.4)$ & $0(0.0)$ & $1(1.8)$ & $0(0.0)$ & $0(0.0)$ & $0(0.0)$ \\
\hline \multicolumn{7}{|l|}{ Socioeconomic status } \\
\hline Q1 (lowest) & $48(20.7)$ & $41(23.3)$ & $7(12.5)$ & $23(16.7)$ & $15-20(17.2-23.0)$ & 5-10 (9.8-19.6) \\
\hline Missing & $23(9.9)$ & $16(9.1)$ & $7(12.5)$ & 19 (13.8) & $11(12.6)$ & $8(15.7)$ \\
\hline \multicolumn{7}{|l|}{ Surgery } \\
\hline Simple & $176(75.6)$ & $176(100.0)$ & - & $87(63.0)$ & $87(100.0)$ & - \\
\hline Extended & $56(24.1)$ & - & $56(100.0)$ & $51(37.0)$ & - & $51(100.0)$ \\
\hline Upfront & $23(9.9)$ & - & $23(41.1)$ & $36(26.1)$ & - & $36(70.6)$ \\
\hline Delayed & $33(14.2)$ & - & $33(58.9)$ & $15(10.9)$ & - & $15(29.4)$ \\
\hline Adjuvant treatment & $29(12.5)$ & $12(6.8)$ & $17(30.4)$ & $19(13.8)$ & $10(11.5)$ & $9(17.6)$ \\
\hline \multicolumn{7}{|l|}{ Grade } \\
\hline Well & $45(19.4)$ & $33(18.8)$ & $12(21.4)$ & $21(15.2)$ & $10(11.5)$ & $11(21.6)$ \\
\hline Moderate & 106 (45.7) & $82(46.6)$ & $24(42.8)$ & $53(38.4)$ & $35(40.2)$ & $18(35.3)$ \\
\hline Poor & $67(28.9)$ & $48(27.3)$ & 19 (33.9) & $56(40.6)$ & $38(43.7)$ & $18(35.3)$ \\
\hline Absent & 89 (38.4) & 64 (36.4) & 25 (44.6) & $62(44.9)$ & $35(40.2)$ & $31(60.8)$ \\
\hline Missing & $48(20.7)$ & $40(22.7)$ & $8(14.3)$ & $37(26.8)$ & $25(28.7)$ & $12(23.5)$ \\
\hline \multicolumn{7}{|l|}{ Margin status } \\
\hline Negative & $142(61.2)$ & 89 (50.6) & $53(94.6)$ & $59(42.8)$ & $22(25.3)$ & $37(72.5)$ \\
\hline Any positive & $43(18.5)$ & $40-45(22.7-25.6)$ & $<6(0.0-8.9) \dagger$ & $69(50.0)$ & $55(63.2)$ & $14(27.4)$ \\
\hline Missing & $46(19.8)$ & $40-45(22.7-25.6)$ & $<6(0.0-8.9) \dagger$ & $10(7.2)$ & $10(11.5)$ & $0(0.0)$ \\
\hline \multicolumn{7}{|l|}{ Lymph node status } \\
\hline Negative & $50(21.6)$ & $29(16.5)$ & $21(37.5)$ & $27(19.6)$ & $<6(0.0-5.7) \dagger$ & $20-25(39.2-49.0)$ \\
\hline Positive & $63(27.2)$ & 30-35 (17.0-19.9) & $30-35(53.4-62.5)$ & 46 (33.3) & $23(26.4)$ & $23(45.1)$ \\
\hline Missing & 119 (51.3) & $115-120(65.3-68.2)$ & $<6(0.0-8.9) \dagger$ & $65(47.1)$ & $55-60(63.2-69.0)$ & $<6(0.0-9.8) \dagger$ \\
\hline \multicolumn{7}{|l|}{ No. of nodes } \\
\hline 0 & $124(53.4)$ & $120-124(68.2-70.4)$ & $<6(0.0-8.9) \dagger$ & $67(48.6)$ & $60(69.0)$ & $7(13.7)$ \\
\hline 1 & $51(22.0)$ & $40(22.7)$ & $11(19.6)$ & $35(25.4)$ & $23(26.4)$ & $12(23.5)$ \\
\hline 2 & $21(9.0)$ & $15(8.5)$ & $6(10.7)$ & $12(8.7)$ & $<6(0.0-5.7) \dagger$ & 5-10 (9.8-19.6) \\
\hline$\geq 3$ & $36(15.5)$ & $<6(0.0-2.8) \dagger$ & $35-40(60.2-71.4)$ & $24(17.4)$ & $<6(0.0-5.7) \dagger$ & $20-25(39.2-49.0)$ \\
\hline Mean \pm SD & $1.31 \pm 2.3$ & $0.4 \pm 0.7$ & $4.1 \pm 3.2$ & $1.6 \pm 2.8$ & $0.3 \pm 0.6$ & $3.7 \pm 3.8$ \\
\hline
\end{tabular}




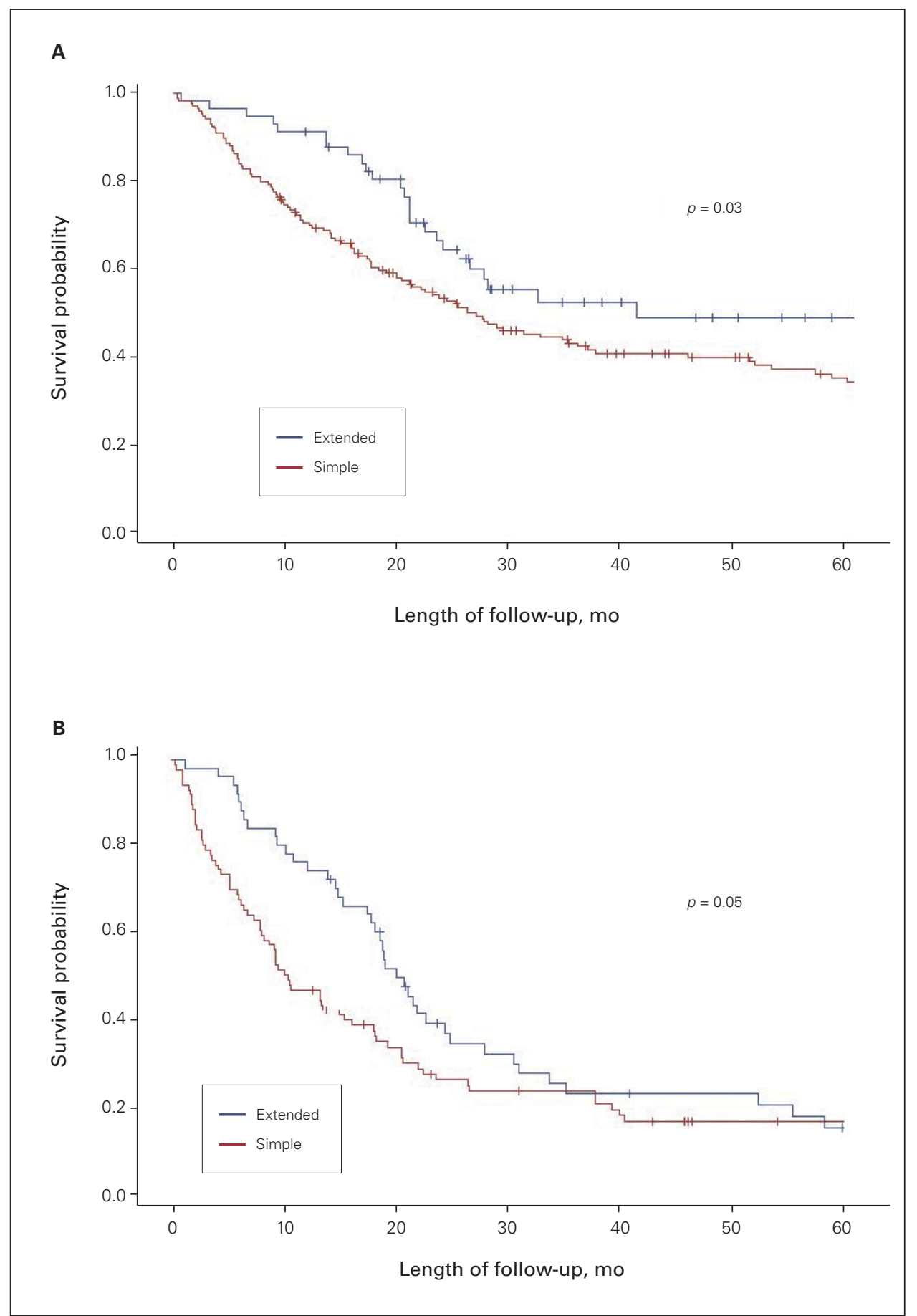

Fig. 2. Kaplan-Meier overall survival analysis for stage T2 (A) and T3 (B) gallbladder cancer by type of resection. $+=$ censored.

cholecystectomy ( $p=0.05$ ) (Figure 2B). The corresponding 5 -year cancer-specific survival rates were $24.4 \%$ and $17.0 \%(p=0.06)$. The median 5 -year overall survival was 21.5 months for extended resection, compared to 10.5 months for simple cholecystectomy $(p=0.001)$. The 30 -day postoperative mortality rate was $2.2 \%$ for the simple cholecystectomy group and $0 \%$ for the extendedresection group.

\section{Factors associated with survival}

Table 2 presents the Cox model results. For T2 disease, in multivariate analysis, extended resection was associated with improved overall survival compared to simple resection (hazard ratio [HR] 0.51, 95\% confidence interval [CI] $0.30-0.97)$. Patients with a high grade of differentiation (HR 3.42, 95\% CI 1.92-6.08), presence of lymphovascular 


\begin{tabular}{|c|c|c|c|c|}
\hline \multirow[b]{2}{*}{ Variable } & \multicolumn{2}{|c|}{ T2; HR (95\% Cl) } & \multicolumn{2}{|c|}{ T3; HR (95\% Cl) } \\
\hline & Univariate & Multivariate & Univariate & Multivariate \\
\hline \multicolumn{5}{|l|}{ Surgery } \\
\hline Simple & Ref & Ref & Ref & Ref \\
\hline Extended & $0.68(0.39-1.00)$ & $0.51(0.30-0.97)$ & $0.70(0.47-1.04)$ & $1.09(0.62-1.92)$ \\
\hline \multicolumn{5}{|l|}{ Sex } \\
\hline Male & Ref & Ref & Ref & Ref \\
\hline Female & $0.79(0.56-1.12)$ & $0.70(0.49-1.01)$ & $0.64(0.43-0.96)$ & $0.66(0.43-1.00)$ \\
\hline Age & $1.01(0.99-1.03)$ & $1.01(0.99-1.03)$ & $1.01(1.01-1.05)$ & $1.04(1.02-1.06)$ \\
\hline Socioeconomic status & & - & & - \\
\hline Q1 (lowest) & Ref & & Ref & \\
\hline Q2 & $1.07(0.63-1.80)$ & & $1.16(0.63-2.12)$ & \\
\hline $\mathrm{Q} 3$ & $0.97(0.56-1.66)$ & & $1.04(0.55-1.94)$ & \\
\hline Q4 & $0.78(0.40-1.51)$ & & $0.99(0.50-1.96)$ & \\
\hline Q5 (highest) & $1.03(0.59-1.81)$ & & $1.77(0.58-2.36)$ & \\
\hline Adjuvant treatment & & - & & - \\
\hline No & Ref & & Ref & \\
\hline Yes & $1.26(0.75-2.13)$ & & $1.11(0.60-1.69)$ & \\
\hline \multicolumn{5}{|l|}{ Grade } \\
\hline Well & Ref & Ref & Ref & Ref \\
\hline Moderate & $2.34(1.32-4.13)$ & $2.08(1.17-3.69)$ & $1.06(0.61-1.84)$ & $1.18(0.67-2.11)$ \\
\hline Poor & $3.51(1.95-6.31)$ & $3.42(1.92-6.08)$ & $1.38(0.70-2.38)$ & $1.61(0.92-2.83)$ \\
\hline \multicolumn{5}{|l|}{ Perineural invasion } \\
\hline Absent & Ref & Ref & Ref & Ref \\
\hline Present & $2.12(1.33-3.38)$ & $1.58(0.98-2.54)$ & $0.93(0.51-1.68)$ & $1.03(0.57-1.84)$ \\
\hline Unknown & $1.49(0.92-2.42)$ & $1.08(0.65-1.78)$ & $1.34(0.73-2.46)$ & $1.22(0.65-2.29)$ \\
\hline \multicolumn{5}{|c|}{ Lymphovascular invasion } \\
\hline Absent & Ref & Ref & Ref & Ref \\
\hline Present & $1.75(1.16-2.64)$ & $1.75(1.16-2.64)$ & $1.22(0.76-1.95)$ & $1.07(0.65-1.76)$ \\
\hline Unknown & $1.30(0.78-2.16)$ & $1.30(0.78-2.16)$ & $0.83(0.53-1.56)$ & $0.73(0.42-1.27)$ \\
\hline \multicolumn{5}{|l|}{ Lymph node status } \\
\hline Negative & Ref & Ref & Ref & Ref \\
\hline Positive & $1.71(1.03-2.85)$ & $1.78(1.03-3.08)$ & $1.71(1.13-3.45)$ & $1.69(0.93-3.07)$ \\
\hline Unknown & $1.28(0.80-2.05)$ & $1.03(0.62-1.72)$ & $1.28(1.14-3.34)$ & $1.78(1.00-3.15)$ \\
\hline
\end{tabular}

invasion (HR 1.75, 95\% CI 1.16-2.64) and presence of positive lymph nodes (HR 1.78, 95\% CI 1.03-3.08) had worse overall survival. Female sex showed a trend toward better overall survival compared to male sex (HR 0.70, 95\% CI 0.49-1.01).

In patients with T3 tumours, multivariate analysis did not show a survival benefit for extended resection (HR 1.09, 95\% CI 0.62-1.92) (Table 2). In the full model, older age (HR 1.04, 95\% CI 1.02-1.06) showed worse prognosis, but female sex was protective (HR 0.66, 95\% CI 0.43-1.00).

When we tested interaction terms between the type of surgery (exposure variable) and the other potential confounders, the results showed a trend toward a significant multiplicative interaction between lymph node status and type of surgery $(p=0.1)$. We therefore performed a subgroup analysis for T3 disease stratified by lymph node status. There was a trend toward improved survival among patients in this group who underwent extended surgery and had negative node status (HR 0.20 , 95\% CI $0.03-$ 1.06); no survival benefit was seen for patients who underwent extended resection and had positive or unknown node status (Table 3 ). No other pathology variables showed an association with survival for node-positive or node-negative disease. Female sex was suggestive of a protective effect in node-positive disease (HR 0.47, 95\% CI $0.21-1.04)$.

\section{Discussion}

Several important findings emerged from this study of the surgical practice patterns and outcomes in T2 and T3 gallbladder cancer in Ontario. The use of extended resection was modest: only $24 \%$ of patients with T2 disease and $37 \%$ of those with T3 disease underwent extended resection. In the T2 group, the overall survival among patients who underwent extended resection was significantly better 


\begin{tabular}{|c|c|c|c|}
\hline \multirow[b]{2}{*}{ Variable } & \multicolumn{3}{|c|}{ Lymph node status; HR (95\% Cl) } \\
\hline & $\begin{array}{l}\text { Negative } \\
n=27^{*}\end{array}$ & $\begin{array}{l}\text { Positive } \\
n=46 \dagger\end{array}$ & $\begin{array}{c}\text { Unknown } \\
60>n<66 \ddagger\end{array}$ \\
\hline \multicolumn{4}{|l|}{ Surgery } \\
\hline Simple & Ref & Ref & Ref \\
\hline Extended & $0.20(0.03-1.06)$ & $0.63(0.30-1.34)$ & $2.06(0.78-5.49)$ \\
\hline \multicolumn{4}{|l|}{ Sex } \\
\hline Male & Ref & Ref & Ref \\
\hline Female & $1.09(0.32-3.70)$ & $0.47(0.21-1.04)$ & $0.71(0.37-1.34)$ \\
\hline Age & $0.99(0.92-1.07)$ & $1.00(0.97-1.04)$ & $1.05(1.02-1.08)$ \\
\hline \multicolumn{4}{|l|}{ Grade } \\
\hline Well & Ref & Ref & Ref \\
\hline Moderate & $0.96(0.16-5.72)$ & $0.97(0.34-2.79)$ & $1.07(0.45-2.55)$ \\
\hline Poor & $2.10(0.31-14.5)$ & $2.22(0.83-5.94)$ & $1.15(0.48-2.75)$ \\
\hline \multicolumn{4}{|c|}{ Perineural invasion } \\
\hline Absent & Ref & Ref & Ref \\
\hline Present & $0.51(0.08-3.58)$ & $1.66(0.57-4.84)$ & $0.93(0.37-2.30)$ \\
\hline Unknown & $0.64(0.10-4.00)$ & $0.90(0.24-3.34)$ & $1.52(0.59-3.93)$ \\
\hline \multicolumn{4}{|c|}{ Lymphovascular invasion } \\
\hline Absent & Ref & Ref & Ref \\
\hline Present & $1.71(0.38-7.77)$ & $0.52(0.14-2.02)$ & $1.78(0.84-3.79)$ \\
\hline Unknown & $0.13(0.01-1.47)$ & $0.39(0.08-1.79)$ & $0.69(0.27-1.78)$ \\
\hline
\end{tabular}

than in patients who had simple cholecystectomy, with an HR of 0.51. In the T3 group, a trend toward improved survival was noted only among node-negative patients who underwent extended resection.

Although the proportions of patients who underwent extended resection in the present study were modest, they were higher than those reported in a 2009 US study using population-level data, $5.2 \%$ for $\mathrm{T} 2$ gallbladder cancer and $13.3 \%$ for T3 gallbladder cancer. ${ }^{6}$ Nevertheless, the small proportion of patients who underwent extended resection is of concern in view of our results. The current National Comprehensive Cancer Network guidelines recommend extended cholecystectomy for all T2 gallbladder cancers. ${ }^{4}$ Support for extended resection is based on several older observational studies. ${ }^{6-9}$ A population-based study by Coburn and colleagues ${ }^{10}$ using data from the Surveillance, Epidemiology, and End Results (SEER) Program registry showed a significant improvement in survival for extended versus simple cholecystectomy on KaplanMeier analysis, but this effect was attenuated in their multivariate model.

However, the benefit of extended resection has recently been questioned. ${ }^{11-14}$ Based on a series of 21 patients, Watson and colleagues ${ }^{13}$ argued that extended resection for T2 gallbladder cancer merely upstages the disease, with no change in overall survival. Cho and colleagues ${ }^{14}$ also reported that hepatic resection had no significant effect on survival in patients with T2 gallbladder cancer, with only node metastases being a predictor of overall survival. In contrast, our study clearly shows that, in addition to absent nodal metastasis, lack of lymphovascular invasion, a low grade of differentiation and extended resection are all independent predictors of better overall survival.

With regard to T3 gallbladder cancer, on unadjusted Kaplan-Meier analysis, we found improved overall survival for extended resection compared to simple cholecystectomy. However, the benefit of extended resection was attenuated in the adjusted multivariate analysis. Two large US population-based studies using the same SEER data also did not show an improvement in overall survival between simple cholecystectomy and extended resection for T3 cancers. ${ }^{6}, 10$

Subgroup analysis for T3 disease stratified by lymph node status showed a trend toward improved overall survival with extended resection in node-negative patients compared to node-positive disease or unknown nodal status, although the sample was small: among the 27 patients with node-negative T3 disease, there were fewer than 6 in the simple cholecystectomy group and 23 in the extendedresection group. This result is in keeping with previous single-institution studies. Benoist and colleagues ${ }^{15}$ reported that there were no long-term survivors with node-positive disease among 21 patients who underwent radical resection with portal lymph node dissection. They concluded that 
radical resection should be considered only in the absence of regional lymph node metastasis. ${ }^{15}$ Dixon and colleagues ${ }^{16}$ reported improved survival among 99 patients with gallbladder cancer who underwent curative extended resection. However, there were no 5 -year survivors with node-positive disease in their series, which suggests that aggressive surgery rarely achieves long-term survival in patients who are node-positive.

In our cohort of 46 patients with node-positive T3 disease, there did not appear to be improved survival among those who underwent extended resection compared to those who underwent simple cholecystectomy. However, the point estimate of the HR (0.63) still favoured extended resection. Therefore, these results should be interpreted with caution and should not automatically deter surgeons from performing extended resection in node-positive patients. In their cohort of 116 patients with gallbladder cancer, Sakata and colleagues ${ }^{17}$ noted worse outcomes in node-positive patients than in those without regional nodal disease; however, radical resection was found to be effective against up to 3 positive lymph nodes, a result echoed in the study by Shirai and colleagues. ${ }^{18}$ Furthermore, although our study did not show an effect for adjuvant treatment in gallbladder cancer, Tran Cao and colleagues ${ }^{19}$ reported that the best outcome for node-positive patients was R0 resection followed by adjuvant chemotherapy and radiation, whereas adjuvant chemotherapy alone did not prove beneficial.

In keeping with previous studies, ${ }^{6,20}$ younger age and female sex showed a protective effect in T3 disease in the present study. However, the sex-specific factors that influence the prognosis of patients with gallbladder cancer remain unknown.

\section{Limitations}

The strength of our study, in comparison to previous population-based studies, ${ }^{6,10}$ lies in the availability of key oncologic variables such as adjuvant treatment data and pathology variables, which allows for a more comprehensive assessment of the role of aggressive surgery for gallbladder cancer. Limitations include that we used a retrospective database and had a modest sample size, both a result and reflection of the rarity of gallbladder cancer. Furthermore, as in SEER-based population-level studies, ${ }^{6,10}$ the database does not contain variables related to patient comorbidities, However, in an aggressive disease such as gallbladder cancer, the effect of other comorbidities may be marginal. Moreover, to mitigate the effects of comorbidity, we calculated cancer-specific survival outcomes in the subset of the population for whom these data were available (2002-2010). More than $95 \%$ of this cohort had cancer as the cause of death, and the median and 5 -year survival data were concordant with the overall survival results from other reports. ${ }^{6,7,10}$

\section{Conclusion}

Extended resection, well-differentiated tumours, absence of node-positive disease and absence of lymphovascular invasion were all independently associated with improved overall survival in patients with $\mathrm{T} 2$ gallbladder cancer. These results add to the existing literature on the benefits of extended resection for T2 disease. For T3 disease, extended resection appears most beneficial in node-negative disease. The finding that extended resection was offered only to a small proportion of eligible patients with gallbladder cancer in Ontario highlights the need for improved knowledge translation at national surgical meetings.

Affiliations: From the Department of Surgery, Queen's University, Kingston, Ont. (Tharmalingam, Nanji); the Department of Medicine, Queen's University, Kingston, Ont. (Flemming); the Department of Public Health Sciences, Queen's University, Kingston, Ont. (Flemming, Richardson); the Department of Pathology and Molecular Medicine, Queen's University, Kingston, Ont. (Hurlbut); and the Department of Surgery, Mayo Clinic, Rochester, Minn. (Cleary).

Competing interests: Jennifer Flemming reports consulting fees from Gilead Sciences for participation in an academic conference planning committee. Sean Cleary reports consulting fees from Olympus, Ethicon and Erbe, and honoraria from Ethicon. No other competing interests were declared.

Contributors: S. Tharmalingam, J. Flemming, H. Richardson, S. Cleary and S. Nanji designed the study. S. Tharmalingam and D. Hurlbut acquired the data, which S. Tharmalingam, J. Flemming, H. Richardson, S. Cleary and S. Nanji analyzed. S. Tharmalingam and S. Nanji wrote the manuscript, which all authors critically revised. All authors gave final approval of the article to be published.

Content licence: This is an Open Access article distributed in accordance with the terms of the Creative Commons Attribution (CC BYNC-ND 4.0) licence, which permits use, distribution and reproduction in any medium, provided that the original publication is properly cited, the use is noncommercial (i.e., research or educational use), and no modifications or adaptations are made. See: https://creativecommons. org/licenses/by-nc-nd/4.0/.

\section{References}

1. Flemming J, Zhang-Salomons J, Nanji S, et al. Increased incidence but improved median overall survival for biliary tract cancers diagnosed in Ontario from 1994 through 2012: a population-based study. Cancer 2016;122:2534-43.

2. Torre LA, Siegel R, Islami F, et al. Worldwide burden of and trends in mortality from gallbladder and other biliary tract cancers. Clin Gastroenterol Hepatol 2018;16:427-37.

3. Hickman L, Contreras C. Gallbladder cancer. Diagnosis, surgical management, and adjuvant therapies. Surg Clin North Am 2019;99:337-55.

4. National Comprehensive Cancer Network. Hepatobiliary cancers. Version 5.2021. Available: https://www.nccn.org/guidelines/ guidelines-detail? category=1\&id=1438 (accessed 2019 Apr. 10).

5. Hall S, Schulze K, Groome P, et al. Using cancer registry data for survival studies: the example of the Ontario Cancer Registry. 7 Clin Epidemiol 2006;59:67-76.

6. Jensen EH, Abraham A, Habermann EB, et al. A critical analysis of the surgical management of early-stage gallbladder cancer in the United States. 7 Gastrointest Surg 2009;13:722-7.

7. Cleary SP, Dawson LA, Knox JJ, et al. Cancer of the gallbladder and extrahepatic bile ducts. Curr Probl Surg 2007;44:396-482.

8. de Aretxabala XA, Roa IS, Burgos LA, et al. Curative resection in potentially resectable tumours of the gallbladder. Eur F Surg 1997;163:419-26. 
9. Fong Y, Heffernan N, Blumgart LH. Gallbladder carcinoma discovered during laparoscopic cholecystectomy: aggressive reresection is beneficial. Cancer 1998;83:423-7.

10. Coburn NG, Cleary SP, Tan JC, et al. Surgery for gallbladder cancer: a population-based analysis. 7 Am Coll Surg 2008;207:371-82.

11. Soreide K. Research gaps and unanswered questions in gallbladder cancer. HPB (Oxford) 2018;20:685-6.

12. Lee SE, Kim SW, Han HS, et al.; Korean Pancreas Surgery Club. Surgical strategy for T2 gallbladder cancer: nationwide multicenter survey in Korea. 7 Korean Med Sci 2018;33:e186.

13. Watson H, Dasari B, Wyatt J, et al. Does a second resection provide a survival benefit in patients diagnosed with incidental T1b/T2 gallbladder cancer following cholecystectomy? HPB (Oxford) 2017;19: 104-7.

14. Cho JK, Lee W, Jang JY, et al. Validation of the oncologic effect of hepatic resection for $\mathrm{T} 2$ gallbladder cancer: a retrospective study. World 7 Surg Oncol 2019;17:8.
15. Benoist S, Panis Y, Fagniez PL. Long-term results after curative resection for carcinoma of the gallbladder. French University Association for Surgical Research. Am 7 Surg 1998;175:118-22.

16. Dixon E, Vollmer CM Jr, Sahajpal A, et al. An aggressive surgical approach leads to improved survival in patients with gallbladder cancer: a 12-year study at a North American center. Ann Surg 2005;241:385-94.

17. Sakata J, Shirai Y, Wakai T, et al. Number of positive lymph nodes independently determines the prognosis after resection in patients with gallbladder carcinoma. Ann Surg Oncol 2010;17:1831-40.

18. Shirai Y, Sakata J, Wakai T, et al. Assessment of lymph node status in gallbladder cancer: location, number, or ratio of positive nodes. World 7 Surg Oncol 2012;10:87.

19. Tran Cao HS, Zhang Q, Sada YH, et al. The role of surgery and adjuvant therapy in lymph node-positive cancers of the gallbladder and intrahepatic bile ducts. Cancer 2018;124:74-83.

20. Hundal R, Shaffer EA. Gallbladder cancer: epidemiology and outcomes. Clin Epidemiol 2014;6:99-109. 